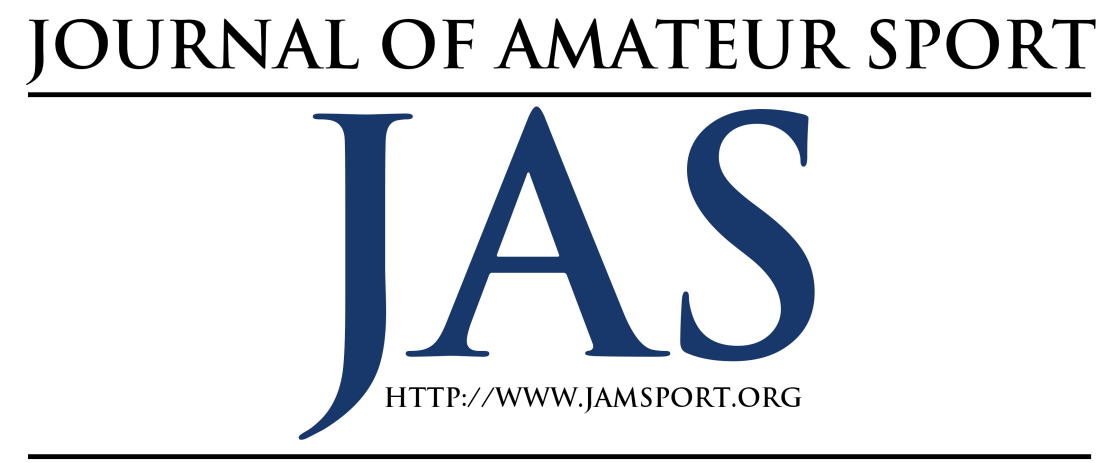

\title{
Examining Sport Team Identification, Social Connections, and Social Well-being among High School Students
}

\author{
Daniel L. Wann \\ Matthew Brasher
}

Paula J. Waddill

Sagan Ladd

\section{Murray State University}

\begin{abstract}
Past research has found that sport team identification is positively correlated with social psychological health (Phua, 2012; Wann \& Weaver, 2009) including work testing adolescent fans (Wann, Brasher, Thomas, \& Scheuchner, in press). The current study was designed to extend previous investigations by examining the relationship between team identification and the establishment and maintenance of social connections. Data from 177 high school students confirmed expectations as identification with a high school football team was positively correlated with both social well-being and social connections. However, social connections were not found to mediate the relationship between identification and well-being, contrary to the team identification - social psychological health model (Wann, 2006b).
\end{abstract}

$\mathrm{H}$ umans have an innate need to belong with various groups (Baumeister \& Leary, 1995;

Lavigne, Vallerand, \& Crevier-Braud, 2011). As noted by Lambert and his colleagues (2013), "multiple lines of research have provided evidence that social relationships are crucial to finding meaning in life" (p. 1418). By establishing and maintaining connections to others, individuals receive a variety of well-being benefits (Compton, 2005; Lee \& Robbins, 1998). For instance, membership in and identification with a variety of groups are related to well-being: including religious organizations (Diener \& Clifton, 2002), high school peer groups (Connolly, White, Stevens, \& Burnstein, 1987), work/employment groups (Haughey, 1993), and minority groups (Branscombe, Schmitt, \& Harvey, 1999). The need to 
belong is also manifested through participation in leisure pursuits (Glover, Parry, \& Shinew, 2005; Maynard \& Kleiber, 2005) and leisure activities do impact happiness (Argyle, 1999), leading Compton (2005) to conclude that, "Any discussion of well-being must eventually take a look at leisure" (p. 67). This includes participation in leisure activities revolving around sport (Wann, 1997). For example, the need for affiliation is a common motive for participation in athletics (Alderman, 1978; Alderman \& Wood, 1976; Buonamano, Cei, \& Mussino, 1995).

The need to belong and the desire to gain connections with others are also relevant to participation in sport as a fan and/or spectator (Gwinner \& Swanson, 2003; Theodorakis, Wann, Nassis, \& Luellen, 2012; Wann, Melnick, Russell, \& Pease, 2001). For instance, similar to participation in sport as an athlete, the need to affiliate is a common factor underlying the desire of fans to follow a sport, team, or player (Lee \& Armstrong, 2008; Wann, Grieve, Zapalac, \& Pease, 2008; Wigley, Sagas, \& Ashley, 2002). Connections gained via sport fandom and spectating can have important positive social psychological consequences (Pringle, 2004; Theodorakis et al., 2012; Wann, 2006a). In fact, Andriessen and Krysinska (2011) concluded that being a fan and following a team "creates camaraderie, a sense of belongingness and being cared for and can result in sportsrelated 'pulling together' which might protect against suicide" (p. 180).
Interestingly, empirical research has substantiated their claims (e.g., Joiner, Hollar, \& Van Orden, 2006).

The current research was designed to investigate the belongingness of sport fans by furthering our understanding of the relationships among sport team identification, social connectedness (i.e., belonging), and social-psychological health. Specifically, we were interested in extending previous efforts by examining these relationships among younger (i.e., adolescent) fans. In many ways, the experiences of younger fans (and youth sport in general) are under-studied within the areas of sport psychology, sport sociology, and sport marketing/management. However, research that has been conducted indicates that the youth sport experience can have important consequences for participants and spectators alike. As for participants, the literature suggests that involvement in youth sports can positively impact the young athletes. Specifically, youth sport participation has been linked with reduced suicidal thinking (Taliaferro, Rienzo, Miller, Pigg, \& Dodd, 2010), greater selfconfidence (Jones, Dunn, Holt, Sullivan, \& Bloom, 2011), and enhanced self-esteem (Kamal, Blais, Kelly, \& Ekstrand, 1995; Taylor \& Turek, 2010). As for fans and spectators of youth sport, research suggests that interest in youth sport teams may be related to well-being and the establishment of social bonds (Reding, Grieve, Derryberry, \& Paquin, 2011). However, other work 
indicates that there is a darker side to identifying with a youth team. For instance, consider a recent investigation conducted by Wann, Weaver, Belva, Ladd, and Armstrong (2015) examining the verbally aggressive actions of spectators at youth baseball games. These researchers found that persons with a stronger attachment to one of the teams in the competition reported significantly greater levels of verbal aggression in response to on-field actions. Thus, given the impact that youth sport can have on both players and fans, additional research is warranted.

In the literature review to follow, we examine the current body of empirical research and theory in this area, as well as providing justification for the current study.

\section{Literature Review}

The team identification - social psychological health model (TI-SPHM; Wann, 2006c) was designed to explain the psychological impact of gaining connections to others via sport fandom. According to this model, individuals can gain both enduring connections and temporary connections via their sport team identification. Enduring connections occur when an individual resides in the geographic location in which a team is found. For example, a Green Bay Packers National Football League (NFL) fan who lives in Green Bay will consistency find himself or herself in the company of other fans of the team. These other fans provide the individual with enduring connections.
Temporary connections, on the other hand, are short-term relationships acquired by persons who do not reside in a team's geographic locale. For instance, imagine if the Packers fan described above lived in a distant city, for example, Nashville, TN. Given Nashville's distance from Green Bay and the fact that Nashville has its own NFL team (the Tennessee Titans), the fan will not have enduring connections to others as a result of his Packers fandom. However, if this person learns that several dozen similarly displaced Packers fans gather each Sunday at a local sports bar to watch the team, the fan will, while watching the team in the company of other Packers fans, be able to gain temporary social connections as a consequence of his or her identification with the team. According to the model, enduring and temporary connections are expected to lead to improved social psychological health. Threats to the fan's identity as a team follower (e.g., poor team performance, player arrests) and attempts to cope with the identity threats are expected to impact the pattern as well.

Research has supported much of Wann's (2006c) model. For instance, team identification has consistently been associated with positive social psychological health including lower levels of alienation (Branscombe \& Wann, 1991), collective (group-level) self-esteem (Phua, 2012), extraversion (Reding et al., 2011), and social integration (Wann \& Weaver, 2009). Furthermore, fans experience a variety of threats to their identity as a team follower, 
such as poor team performance (End et al., 2003) and unscrupulous and/or illegal behaviors by players (Fink, Parker, Brett, \& Higgins, 2009). Additionally, research has identified a number of coping strategies utilized by fans to combat these threats including biased attributions (Sherman, Kinias, Major, Kim, \& Prenovost, 2007), positively biased predictions of future performance (Markman \& Hirt, 2002), superstitious actions (Wann et al., 2013), and utilizing retroactive pessimism (Wann, Grieve, Waddill, \& Martin, 2008).

However, the component of the model most relevant to the current investigation concerns social connections related to following a team and, specifically, the interrelationships among team identification, social connections, and social psychological health. As noted, the model predicts that identification with a local team will result in social connections, which will then subsequently lead to social psychological health. Previous research has established that fans do indeed establish and maintain connections/social capital with others as a result of their interest in a team (Clopton, 2008; Clopton \& Finch, 2010, Kelley \& Tian, 2004; Palmer \& Thompson, 2007). However, investigations of the precise patterns of relationships among the critical variables have only been partially supportive of the model. For instance, consider the work by Wann, Waddill, Polk, and Weaver (2011). These authors asked college students to complete a questionnaire packet assessing their level of identification with the local university men's basketball team, the extent to which they gained and maintained connections with others via their involvement with the team, and social psychological health. Simple correlations among the variables generally supported the TI-SPHM. For example, as expected, team identification was positively correlated with several indices of social psychological health. Also as predicted, identification was positively related to a variety of assessments of connections derived via the team. However, subsequent analyses failed to support the hypothesis that connections would mediate the relationship between identification and social well-being. Rather, the data indicated that team identification had a direct relationship with both social connections and social well-being. Based on their data and analyses, Wann and his colleagues concluded that modifications to the model may be warranted.

\section{The Current Study and Hypotheses}

As noted above, the current investigation was designed to further test the TI-SPHM and examine the interrelationships among identification, connections, and well-being. Given that prior work had almost exclusively examined college student samples, we chose to extend past research by investigating high school athletics and adolescent fans. A few studies have tested various components of Wann's model within the realm of high school sports. For example, Reding et al. (2011) examined the relationships among 
identification with high school football teams, social connections, and social wellbeing. As expected and consistent with the TI-SPHM, team identification was a significant unique predictor of both social connections and social psychological health. However, although this investigation was an examination of Wann's model within the context of high school sports, the participants were adults. Wann, Brasher, Thomas, and Scheuchner (in press) extended this research by examining identification with a high school football team and well-being among adolescent students. Their results indicated strong support for the model and replicated previous work with college student (e.g., Branscombe \& Wann, 1991; Wann \& Weaver, 2009) and elderly populations (Wann, Rogers, Dooley, \& Foley, 2011). Specifically, identification with the high school's football team was a significant predictor of social well-being for students at that school (higher levels of identification corresponded with higher levels of social life satisfaction and lower levels of social isolation).

Thus, it appears that the team identification - social psychological health model (Wann, 2006c) can be generalized to high school sports and among high school fans. However, the previous work within high school athletics had yet to sufficiently examine the interrelations among the three critical components of the model (i.e., identification, connections, and well-being). Given that past work had failed to confirm the pattern of effects predicted by the model (e.g., Wann, Waddill, et al., 2011) and researchers had yet to examine these variables with an adolescent sample targeting high school athletics, such an examination was warranted and was the focus of the current investigation. Specifically, we tested the following hypotheses:

Hypothesis 1: It was hypothesized that level of team identification with the high school football team would be positively correlated with establishing and maintaining social connections.

Hypothesis 2: It was hypothesized that there would be a positive correlation between identification with the high school football team and social psychological health.

Hypothesis 3: It was hypothesized that social connections would mediate the relationship between team identification and social well-being.

\section{Method}

\section{Participants}

The original sample consisted of 185 students attending a public mid-sized high school in the mid-south (enrollment was approximately 540 students at the time of testing). However, eight persons returned incomplete protocols and were therefore removed from the sample. Consequently, the final sample consisted of 177 students (94 male; 83 female). They had a mean age of 16.20 years $(S D=1.14)$. The sample consisted of sophomores (54\%) and seniors 
$(46 \%)$ (due to a limitation in participant availability on the day of testing, only sophomores and seniors were available for participation).

\section{Target Football Team}

The target high school football team had been extremely successful in recent seasons, achieving a record of 46 wins and only 7 losses during the previous four years. The team had qualified for the state playoffs in each of those seasons. Testing occurred during the fourth week of October. The team had a record of 4 wins and 3 losses at the time of testing.

\section{Materials and Procedure}

Subsequent to receiving IRB approval and gaining participant/parental consent, respondents were tested in groups in a high school cafeteria. Participants were handed a cover letter describing the study and a questionnaire packet containing four sections. Section one included demographic items assessing age, gender, year in school, whether or not the participant played in the school's marching band (the band routinely performed at half time of football games), and whether or not he/she played on the high school's football team.

Next, participants completed 10 items similar to those developed by Wann, Waddill, and their colleagues (2011). These items assessed the extent to which individuals believed they were able to gain and maintain social connections from their association and identification with their high school's football team. The first two items targeted participants' estimates of the percentage of their friends who were fans of the target team. Specifically, they were asked "What percentage of your friends (from simple acquaintances to closest friends) do you feel are strong and involved fans of (name of team was inserted here)?" and "What percentage of your closest friends do you feel are strong and involved fans of (name of team was inserted here)?" These two items were combined to form a "Percentage of Friends" index. The next two items were combined to form a "Number of Friends" index. These items asked "How many of your friends (from simple acquaintances to closest friends) do you feel are strong and involved fans of (name of team was inserted here)" and "How many of your closest friends do you feel are strong and involved fans of (name of team was inserted here)?" Thus, in the first "Number of Friends" item, participants considered all of their friends while in the second item they were to include only their closest friends.

Next, participants answered six Likertscale items targeting social connections gained through supporting the high school football team. These items read: "To what extent do you feel that being a fan of (name of team was inserted here) helps you maintain your friendships with others?," "To what extent do you feel that being a fan of (name of team was inserted here) helps you establish new friendships?," "To what extent does being a fan of (name of team 
was inserted here) football provide you with the opportunity to spend time with your friends?," "To what extent does being a fan of (name of team was inserted here) football provide you with the opportunity to maintain meaningful social relationships with others?," "To what extent does being a fan of (name of team was inserted here) football provide you with the opportunity to form a bond with your friends?," and "To what extent does being a fan of (name of team was inserted here) football provide you with the opportunity to feel a sense of commonality (i.e., having something in common to share) with your friends?" Response options to these items ranged from 1 (does not help maintain friendships, does not help establish new friends, does not provide the opportunity) to 8 (very much belps maintain friendships, very much helps establish new friends, very much provides the opportunity). Thus, higher numbers reflected greater levels of establishing and maintaining social connections from an association with the team. These six items were combined to form a "Likert-scale Items" index. Wann, Waddill, et al. (2011) found that each of the three aforementioned scales were reliable (Cronbach's alphas: Percentage of Friends $=.923$; Number of Friends $=.604$; Likertscale Index $=.958$ ).

The third section of the questionnaire packet contained the seven-item, Likertscale format Sport Spectator Identification Scale (SSIS; Wann \& Branscombe, 1993) targeting the high school's football team. This reliable and valid scale (see Wann et al.,
2001) has been used in dozens of studies and has been translated into multiple languages including Portuguese (Theodorakis, Wann, Carvalho, \& Sarmento, 2010), Dutch (Melnick \& Wann, 2004), and French (Bernache, Bouchet, \& Lacassagne, 2007). A sample item read, "How much do you see yourself as a fan of (target team)?" Response options ranged from 1 (low identification) to 8 (bigh identification). Thus, higher numbers represented greater levels of team identification.

The fourth and final section contained the five-item Satisfaction with Social Life Scale (SSLS; Wann \& Pierce, 2005). This reliable and valid Likert-scale was based on the Satisfaction with Life Scale (Diener, Emmons, Larsen, \& Griffin, 1985). A sample item read, "I am satisfied with my social life." Response options ranged from 1 (strongly disagree) to 7 (strongly agree). Thus, higher numbers represented greater levels of satisfaction with one's social life.

After completing the questionnaire packet (approximately 15-20 minutes), participants were debriefed and excused from the testing session.

\section{Results}

\section{Preliminary Analyses}

Items on the Percentage of Friends, Number of Friends, Likert-scale Index, SSIS, and SSLS were summed to form indices for each scale. Potential ranges, means, standard deviations, and Cronbach's alphas for all scales appear in Table 1 (all 
scales had acceptable reliability). Gender differences were examined for each measure using a series of one-way ANOVAs. These analyses failed to reveal any significant differences for identification, social life satisfaction, or any of the three measures of social connections. A series of one-way ANOVAs examining year in school and whether or not the participant played in the marching band also failed to reveal any significant differences on the scales. Thus, all subsequent analyses were collapsed across gender, year in school, and membership in the band.

However, differences were found between participants who were members of the football team $(n=22)$ and those who were not $(n=155)$. Specifically, a series of ANOVAs revealed significant differences for Percentage of Friends $[F(1,175)=$ $10.91, p<.001]$, Number of Friends [ $F(1$, $175)=10.38, p<.005]$, Likert-scale Index $[F(1,175)=33.62, p<.001]$, and team identification $[F(1,175)=46.66, p<.001]$. Participants who played on the football team reported higher scores for Percentage of Friends $(M=153.77, S D=49.48)$, Number of Friends $(M=75.23, S D=$ 67.91), Likert-scale Index $(M=41.50, S D=$ 6.75), and identification with the football team $(M=53.05, S D=3.89)$ than persons who were not on the team (Percentage of Friends $M=108.22, S D=61.91$; Number of Friends $M=39.08, S D=46.11$; Likertscale Index $M=25.92, S D=12.33$; identification $M=33.01, S D=13.61)$. There was no difference in SSLS scores $(F$
$<.30, p>.50)$ as a function of whether the participant was a member of the football team. Because those on the football team differed from those not on the team on the majority of measures, membership on the football team was incorporated into the analyses described below.

\section{Identification and Connections}

Correlations among the variables appear in Table 2. Hypothesis 1 stated that level of team identification would be positively correlated with social connections. As revealed in the table and consistent with results reported by Wann, Waddill, and colleagues (2011) on college fans, the hypothesis was supported for each assessment of connectedness (all $r \mathrm{~s}>.50$, all $p$ s $<.001)$. Compared to adolescents with lower levels of team identification, participants with higher levels of identification with the target high school team reported that a greater percentage and number of their friends were fans of the team and they were more likely to believe that they had the opportunity to maintain and establish friendships by being a fan of the team.

However, as noted above, membership on the football team was also related to the measures of connectedness as team players reported greater connections on each of the measures. Thus, we conducted a series of three simple regressions in which level of identification and membership of the football team (coded as $1=$ yes, $2=$ no) served as predictors of the three measures 
of connections. The first regression targeted the Percentage of Friends scale. This analysis revealed that the combined effect of the two predictor variables was significant, $F(2,174)=75.61, p<.001(R=$ $0.862 ; R^{2}=0.465$; adjusted $\left.R^{2}=0.459\right)$. With respect to independent contributions, as hypothesized (Hypothesis 1) team identification accounted for a significant proportion of unique variance in the percentage of friends who were fans of the team $(t=11.50, p<.001 ; B=3.099 ;$ SE $B$ $=0.270 ;$ Beta $=0.717)$. Membership on the football team was not a significant independent contributor $(t=1.39, p>.15$; $B=16.355$; SE $B=11.738$; Beta $=0.087)$.

The second regression involved the Number of Friends scale and the combined effect of the predictors was again significant, $F(2,174)=29.44, p<.001(R=$ $0.503 ; R^{2}=0.253$; adjusted $\left.R^{2}=0.244\right)$.

With respect to independent contributions, as predicted (Hypothesis 1) identification accounted for a significant proportion of unique variance in the number of friends who were fans of the team $(t=6.77, p<$ $.001 ; B=1.752 ;$ SE $B=0.259$; Beta $=$ 0.499). Once again, membership on the football team was not a significant independent contributor $(t=-0.10, p>.90$; $B=-1.153$; SE $B=11.265$; Beta $=-0.008)$.

The third regression examined the Likert-scale Index. This analysis found that combined effect of the predictors was again significant, $F(2,174)=165.81, p<.001(R$ $=0.810 ; R^{2}=0.656$; adjusted $\left.R^{2}=0.652\right)$. With respect to independent contributions, as expected identification accounted for a significant proportion of unique variance in perceptions of maintaining and establishing friendships by being a fan of the team $(t=$ 15.82, $p<.001 ; B=0.708$; SE $B=0.046$; Beta $=0.792)$. And yet again, membership on the football team was not a significant independent contributor $(t=-0.76, p>.40$; $B=-1.485 ;$ SE $B=1.943$; Beta $=-0.038)$.

\section{Identification, Connections, and Well- being}

Hypothesis 2 predicted a positive correlation between identification with the high school football team and social wellbeing (defined as satisfaction with one's social life). Consistent with expectations and past research among high school students (Wann et al., in press), identification and satisfaction were significantly and positively correlated, $r(177)$ $=.19, p<.01$.

We next investigated the prediction (Hypothesis 3) that the relationship between team identification and social life satisfaction was at least partly accounted for (i.e., mediated) by social connections (because membership on the football was not found to account for a significant proportion of variance in the aforementioned regression analyses, this variable was not included in the equations). Three initial requirements must be met for evidence of mediation (Baron \& Kenny, 1986): a significant relationship between the predictor (team identification) and the mediator (social connections); a significant 
relationship between the predictor (team identification) and the dependent variable (social life satisfaction); a significant relationship between the mediator (social connections) and the dependent variable (social life satisfaction). If any of these conditions are not met, then mediation does not exist. Conversely, if each of these criteria is met, then one can test the effect of the mediator on the relationship between the predictor and dependent variables. The relationship between number of friends and social life satisfaction was not significant; therefore this connection variable was not included in the mediation analysis. The remaining set of variables (identification, Percentage of Friends, Likert-scale items, and social life satisfaction) did satisfy all of the criteria and were further evaluated for mediation effects. Although the direct relationship between identification and social life satisfaction was significant $(b=$ $.194, t=2.61, p=.01$ ), Sobel's tests (Baron \& Kenny, 1986) indicated that, contrary to expectations, this relationship was not significantly mediated by either Percentage of Friends (indirect effect $b=.105, z=$ $1.59, p=.113$ ) or the Likert items (indirect effect $b=.009, z=0.098, p=.922$ ).

Although the relationship between team identification and social life satisfaction was not accounted for by social connections, it remained possible that the relationship between identification and social life satisfaction differed as a function of varying amounts of social connections. Thus, a moderated regression analysis was executed.
Measures were converted to $₹$ scores prior to these analyses, a process that obviated the need to center the predictor variables before conducting the moderated regression analysis (Aiken \& West, 1991). Interaction terms were established between identification and each social connection variable. These interaction terms, along with the individual predictors (identification, Percentage of Friends, Number of Friends, Likert items) were entered into the model with social life satisfaction serving as the dependent variable. The results indicated that none of the interaction terms were significant predictors of social life satisfaction (largest $b=.17, t=1.49, p=$ $.138)$.

Based on the aforementioned analyses, it appears that the relationship between team identification and social life satisfaction is neither mediated nor moderated by social connections. Therefore, a final set of analyses examined the direct relationship between identification and social connections via a multivariate regression analysis. This analysis revealed that team identification was a significant predictor of the set of combined social connection variables, Wilks' lambda $=$ 0.301 , multivariate $F=134.16, p<.001$. Univariate results indicated that, compared to persons with lower team identification, persons with greater team identification reported having more friends who were strong and involved fans $(b=0.50, t=7.69$, $p<.001$ ), having a greater percentage of their friends who were strong and involved 
fans $(b=0.68, t=12.18, p<.001)$, and perceiving greater social benefits from being connected to their target team $(b=0.81, t=$ $18.22, p<.001)$.

\section{Discussion}

The purpose of this investigation was to further examine the relationships among sport team identification, social connectedness, and social psychological health. Consistent with the team identification - social psychological health model (Wann, 2006c), previous work had found that team identification was positively correlated with social psychological health (e.g., Branscombe \& Wann, 1991; Phua, 2012; Reding et al., 2011) and the establishment and maintenance of social connections (e.g., Clopton, 2008; Clopton \& Finch, 2010, Kelley \& Tian, 2004).

However, prior work had focused almost exclusively on college-aged samples and previous efforts regarding the patterns of relationships among the variables did not support all phases of the model (Wann et al., 2011). Thus, we replicated and extended past research by examining the fandom of high school students and further investigating the interrelationships among the key components of the model.

Hypothesis 1 predicted that level of team identification would be positively correlated with social connections generated via the team. Consistent with research on college-aged fans (Wann et al., 2011), the results supported expectations, as identification was positively associated with each of the connection measures. That is, among the adolescent sample tested here, higher levels of identification with one's high school team corresponded with a higher number and percentage of friends who were fans of the team and the Likertscale index assessing the extent to which participants believed their fandom for the team assisted in establishing and maintaining connections with others. Thus, the current work reveals that the previously established relationships among sport team identification and social connections extends to younger fans in a scholastic sport setting.

Hypothesis 2 predicted that there would be a positive correlation between identification with the high school football team and satisfaction with one's social life. As expected and consistent with past research testing high school students (Wann et al., in press), identification and satisfaction were significantly and positively correlated. Thus, identification was positively associated with both social connections and social well-being. Preliminary analyses indicated that membership on the football team was also correlated with social connections and wellbeing as those on the team reported higher levels of both. However, regression analyses indicated that it was identification rather than membership on the team that was the critical predictor variable. This substantiates past research also finding that it was one's psychological connection to a 
team, not membership on a team, that was most vital (Wann et al., in press).

Although we were interested in the aforementioned simple relationships between team identification and both social connections and well-being, the primary purpose of the current investigation was to examine the interrelationships among these variables. Based on the TI-SPHM (Wann, 2006c), we predicted that the relationship between team identification and social life satisfaction would be mediated by social connections. However, the results failed to support this pattern of effects. Rather, team identification was found to have a direct effect on social connectedness as well as social life satisfaction. Interestingly, this is precisely the pattern of effects reported by Wann, Waddill, and their associates (2011). These authors concluded that modifications to the model may be needed and, given that the current investigation replicated their pattern of effects, modifications consistent with these studies appear to be necessary.

Combining the current data with those reported by Wann, Waddill, et al. (2011), there appear to be two logical changes that could be made to the model. First, it may simply be that mediation is not a part of the interrelationships among identification, connections, and well-being. Rather, as found in the current data set and by Wann, Waddill, et al., team identification may simply have a direct effect on both connections and social psychological health. Thus, fans with higher levels of identification will have both greater connections generated via the team and more positive social well-being, but the latter two are not related in a mediational form.

However, a second possibility is that both the current study and the work of Wann, Waddill, et al. (2011) failed to adequately assess the "social connectedness" variable. This perspective has recent empirical support in work by Inoue, Funk, Wann, Yoshida, and Nakazawa (in press). These authors also examined the relationships among identification, connections, and social wellbeing. However, rather than simply assess amount of connections (e.g., number, percent) as was done here (and in Wann, Waddill, et al., 2011), these investigators assessed perceptions of instrumental and emotional support. Their research examined participant responses in the aftermath of the Great East Japan earthquake occurring in March, 2011. Spectators of local Japanese professional soccer teams completed scales assessing their identification with the local team, perceptions of post-disaster instrumental and emotional support, and perceptions of post-disaster community cohesion (a component of social well-being, see Keyes, 1998). The results indicated that, as expected and consistent with the TI-SPHM (Wann, 2006c), identification was positively correlated with community cohesion. More importantly, however, emotional support mediated this relationship, thus providing evidence of the patterns of effects predicted 
by Wann's model (no such relationship was found for instrumental support). Thus, the work by Inoue and his associates suggests that the framework hypothesized by Wann (2006c) is valid, but that the key mediating variable is perceived emotional support rather than amount of connectedness.

\section{Suggestions for Future Research}

When combined with previous efforts, findings from the current investigation lead to several suggestions for future research. First, it would be useful to replicate the findings reported by Inoue et al. (in press) with adolescent fans (their work tested an adult population with a mean age of slightly over 39 years).

Secondly, future researchers should consider investigating the relationships among all four variables: team identification, amount of connectedness (as in the current research and Wann, Waddill, et al., 2011), perceptions of emotional support (as in Inoue et al., in press), and social well-being. That is, given that amount of connections has consistently been found to correlate with team identification, it seems premature to fully dismiss the potential importance of this variable. Rather, future investigations should include both amount of connection and perceptions of emotional support to see how the inclusion of both may impact the pattern of effects.

It would also be valuable to conduct additional research examining identification with a different high school sport. Both the current study and the work conducted previously by Wann and associates (in press) focused on high school football. Although football is often a popular high school sport (especially in certain areas of the country such as Texas), other sports can have large fan bases (e.g., high school basketball in Indiana). Research on college and adult populations has found that social well-being is positively correlated with identification with teams playing a variety of sports including baseball (Wann, Keenan, \& Page, 2009), basketball (Branscombe \& Wann, 1991; Wann \& Weaver, 2009), and Australian Rules football (Wann, Dimmock, \& Grove, 2003). Future investigations should attempt to confirm the team identification - well-being relationship with these and other high school sports. In addition, authors may want to investigate identification with female high school sport teams because, to date, there do not appear to be any empirical studies examining the relationship between team identification and social psychological health for women's teams (at any level of competition).

Additionally, researchers should consider extending the current work to even younger populations. Combining the current work with previous studies (e.g., Wann et al., in press; Wann, Rogers et al., 2011; Wann \& Weaver, 2009), the positive relationship between identification with a local sport team and social psychological health has been established with individuals ranging in age from adolescent to late adulthood. However, individuals are socialized into fandom at a very early age 
and many can identify a favorite team before reaching high school (Wann et al., 2001). Based on his research on the development of team loyalty, James (2001) concluded that "children form preferences for sport teams early in life" and that "they are capable of forming a commitment to a sports team as young as age 5 " (p. 233). In fact, a study of National Football League fans found that over one-third of respondents chose age " 0 " as the starting date for their team fandom (James, Walker, \& Kuminka, 2009). Additionally, Gardikiotis, Tsigilis, Theodorakis, and Kyriakopoulos (2014) found that the need to belong was a significant predictor of team identification in elementary school children, many of whom had high levels of identification with their favorite sport team. Given that children can develop a sense of team identification at a young age and issues such as social well-being, connections to others, and self-esteem are critical for this group (Bigler, 1995; Harter, 1993; Wigfield $\&$ Eccles, 1994), an examination of the relationships among team identification, social connections, and social well-being for younger children is warranted. Once they have assessed the team identification, social connections, and social well-being of a young sample (e.g., elementary school children), researchers should consider conducting longitudinal research with this group of participants. That is, once the younger sample has been established, it could be re-tested over several years (e.g., during middle school, high school, and college) in an attempt to detect changes in the relationships among the variables across time. Further, this approach would allow for a cross-lagged methodology and potentially provide critical information on possible causes patterns among the variables (e.g., Wann, 2006b).

Yet another possible avenue for future research could combine the results of the current investigation with work by Heere and his colleagues. Recently, Here and James (2007) presented a theoretical framework predicting that team identification will be related to identification with external organizations (e.g., demographic, vocational, religious, political). Essentially, these authors argue that a fan's identification with a team does not occur in a vacuum. Subsequent research has substantiated their position. For instance, Heere et al. (2011) found that identification with collegiate football teams was significantly associated with identification with other communities, such as with the university as a whole and with the city in which the school resides. Similar results were provided by Heere, James, Yoshida, and Scremin (2011). Given that team identity is associated with other communities (e.g., Heere \& James, 2007) and given that team identification is related to both social connectedness and social well-being (e.g., the current research), it would be interesting to investigate the interrelationships among these variables in amateur settings. That is, it may be that identification with larger communities (e.g., 
the high school as a whole and/or the city in which the school in found) may also influence well-being. Perhaps identification with larger communities provides a complementary source of connections and well-being or maybe team identification with amateur teams moderates the potential relationships between identity with the larger communities and social psychological connections and health. Additional research should be conducted to investigate these possibilities.

And finally, although not directly related to the focus of the current investigation, researchers may want to investigate differences and similarities among high school student-fans and players with respect to their relationships with the team, other fans and players, and well-being. For instance, it would be interesting to determine if the patterns found above also extend to athlete identity (Brewer, Van Raalte, \& Linder, 1993) among the players. Such an investigation may provide additional insight into the relationship between participation in youth sports and potential psychological benefits such as selfesteem enhancement (Kamal et al., 1995; Taylor \& Turek, 2010).

\section{Limitations}

Several limitations of the current investigation warrant mention. First, as noted above, the current study only examined identification with a football team. Thus, future investigations should extend our work to other high school sports to test the generalizability of the findings reported here. Second, the current work tested only one sample from a single school, a small, public high school in the mid-south. Subsequent investigations are needed that test students attending other schools. In particular, additional work is needed on subjects from private schools as well as schools with larger enrollments (and, presumably, larger sport programs). Third, due to a limitation in participant availability on the day of testing, only sophomores and seniors were available for participation. However, it is possible that a student's grade classification could be related to his or her interest in the football team and, subsequently, impact the relationships examined in the current work. For instance, given that they are new to the school, freshmen may be particularly likely to utilize the football team as a method of gaining connections to others. Further, because of their repeated exposure to the team through multiple seasons, juniors and seniors may be particularly likely to strongly identify with school teams. Thus, future research should include students from all grade levels and include this subject variable in the analyses. Fourth, in the current investigation we included membership in the band as a potential important variable. Although participation in the band was not found to be related to the variables of interest, other team support groups may be important and should be studied in subsequent investigations. These groups include, but 
are not limited to, spirit team members, cheerleaders, and members of dance teams.

An additional limitation can be found in the past performance of the target high school football team. As noted above, the target team had experienced a great deal of success in recent seasons. Thus, researchers should expand the current study by investigating adolescent identification with less successful teams. Interestingly, research with college students (and identification with local college teams) indicates that team success is not critical for the establishment of the identification - well-being relationship. Rather, this positive correlation is also found among persons identifying with less successful teams (Wann et al., 2009). However, it would be important to document that this pattern of effects also is found among younger fans.

And finally, it is important to note that social well-being was only operationalized in one way, namely, satisfaction with one's social life. Life satisfaction is a valid component of subjective well-being (Diener et al., 1985). However, social well-being is multidimensional and can be assessed in numerous ways (Keyes, 1998). Thus, future researchers should attempt to replicate the findings reported here with additional assessments of social psychological health (e.g., loneliness, alienation, social selfesteem, social cohesion, etc.).

\section{Conclusion}

Researchers have consistently found positive correlations between team identification and social psychological health (Wann, 2006c) and between identification and social connections (e.g., Clopton, 2008; Clopton \& Finch, 2010; Wann, Waddill, et al., 2011). Based on the team identification - social psychological health model (Wann, 2006c), the current investigation attempted to replicate these relationships with an adolescent sample and to investigate the intercorrelations among the variables. As expected, team identification was positively related to both social well-being and the establishment and maintenance of social connections, thus extending past work to a younger sample. However, social connections did not mediate the relationship between identification and wellbeing, as predicted by the model. Subsequent research should further investigate the relationships and, if necessary, make appropriate refinements to the model. 


\section{References}

Aiken, L. S., \& West, S. G. (1991). Multiple

Regression: Testing and interpreting

interactions. Newbury Park, CA: Sage.

Alderman, R. B. (1978). Strategies for motivating young athletes. In W. Straub (Ed.), Sport psychology: An analysis of athlete behavior (1st ed., pp. 49-61). Ithaca NY: Mouvement Publications.

Alderman, R. B., \& Wood, N. L. (1976). An analysis of incentive motivation in young Canadian athletes. Canadian Journal of Applied Sport Sciences, 1, 169175.

Andriessen, K., \& Krysinska, K. (2011). Spectators' involvement in sports and suicidal behavior: Review of current evidence. In B. D. Geranto (Ed.), Sport psychology (pp. 175-185).

Hauppauge NY: Nova.

Argyle, M. (1999). Causes and correlates of happiness. In D. Kahneman, E. Diener, \& N. Schwarz (Eds.), Wellbeing: The foundations of hedonic psychology (pp. 353-373). New York: Sage.

Baron, R. M., \& Kenny, D. A. (1986). The moderator-mediator variable distinction in social psychological research: Conceptual, strategic, and statistical considerations. Journal of Personality and Social Psychology, 51, 1173-1182.

Baumeister, R. F., \& Leary, M. R. (1995). The need to belong: Desire for interpersonal attachments a fundamental human motivation. Psychological Bulletin, 117, 497-529. Bernache, I., Bouchet, P., \& Lacassagne, M.F. (2007). Spectators' identification with French sports teams: A French adaptation of the Sport Spectator Identification Scale. Perceptual and Motor Skills, 104, 83-90.

Bigler, R. S. (1995). The role of classification skill in moderating environmental influences on children's gender stereotyping: A study of the functional use of gender in the classroom. Child Development, 66, 1072-1087.

Branscombe, N. R., Schmitt, M. T., \& Harvey, R. D. (1999). Perceiving pervasive discrimination among African Americans: Implications for group identification and well-being. Journal of Personality and Social Psychology, 77, 135-149.

Branscombe, N. R., \& Wann, D. L. (1991). The positive social and self-concept consequences of sports team identification. Journal of Sport \& Social Issues, 15, 115-127.

Brewer, B. W., Van Raalte, J. L., \& Linder, D E. (1993). Athletic identity: Hercules' muscles or Achilles' heel? International Journal of Sport Psychology, 24, 237-254.

Buonamano, R., Cei, A., \& Mussino, A. (1995). Participation motivation in Italian youth sport. The Sport Psychologist, 9, 265-281. 
Clopton, A. W. (2008). College sports on campus: Uncovering the link between fan identification and sense of community. International Journal of Sport Management, 9, 343-362.

Clopton, A. W., \& Finch, B. L. (2010). Are college students 'bowling alone?' Examining the contribution of team identification to the social capital of college students. Journal of Sport Behavior, 33, 377-402.

Compton, W. C. (2005). An introduction to positive psychology. Belmont, CA: Thomson Wadsworth.

Connolly, J., White, D., Stevens, R., \& Burnstein, S. (1987). Adolescent selfreports of social activity: Assessments of stability and relations to social adjustment. Journal of Adolescence, 10, 83-95.

Diener, E., \& Clifton, D. (2002). Life satisfaction and religiosity in broad probability samples. Psychological Inquiry, 13, 206-209.

Diener, E., Emmons, R. A., Larsen, R. J., \& Griffin, S. (1985). The Satisfaction with Life Scale. Journal of Personality Assessment, 49, 71-75.

End, C. M., Eaton, J., Campbell, J., Kretschmar, J. M., Mueller, D., \& Dietz-Uhler, B. (2003). Outcome's influence on sport fans' computermediated attributions. International Sports Journal, 7(2), 128-139.

Fink, J. S., Parker, H. M., Brett, M., \& Higgins, J. (2009). Off-field behavior of athletes and team identification:
Using social identity theory and balance theory to explain fan reactions. Journal of Sport Management, 23, 142-155.

Gardikiotis, A., Tsigilis, N., Theodorakis, N. D., \& Kyriakopoulos, P. (2014). Children's sport team identification: Social Psychological processes and developmental perspectives. International Journal of Sport Management, 15, 105-117.

Glover, T. D., Parry, D. C., \& Shinew, K. J. (2005). Building relationships, accessing resources: Mobilizing social capital in community garden contexts. Journal of Leisure Research, 37 , 450-474.

Gwinner, K., \& Swanson, S. R. (2003). A model of fan identification: Antecedents and sponsorship outcomes. Journal of Services Marketing, 17, 275-294.

Harter, S. (1993). Causes and consequences of low self-esteem in children and adolescents. In R. F. Baumeister (Ed.) Self-esteem: The puzzle of low selfregard (pp. 87-116). New York: Plenum.

Haughey, J. C. (1993). Does loyalty in the workplace have a future? Business Ethics Quarterly, 3, 1-16.

Heere, B., \& James, J. (2007). Sports teams and their communities: Examining the influence of external group identities on team identity. Journal of Sport Management, 21, 319-337. 
Heere, B., James, J., Yoshida, M., \& Scremin, G. (2011). The effect of associated group identities on team identity. Journal of Sport Management, 25, 606-621.

Heere, B., Walker, M., Yoshida, M., Ko, Y. J., Jordan, J. S., \& James, J. (2011). Brand community development through associated communities: Grounding community measurement within social identity theory. Journal of Marketing Theory and Practice, 19, 407422.

Inoue, Y., Funk, D. C., Wann, D. L., Yoshida, M., \& Nakazawa, M. (in press). Team identification and postdisaster social well-Being: The mediating role of social support. Group Dynamics: Theory, Research, and Practice.

James, J. D. (2001). The role of cognitive development and socialization in the initial development of team loyalty. Leisure Sciences, 23, 233-261.

James, J. D., Walker, M., \& Kuminka, W. (2009). Becoming a professional football team fan: Differences based on level of team internalization. International Journal of Sport Management, 10, 14-34.

Joiner, T. E., Jr., Hollar, D., \& Van Orden, K. (2006). On Buckeyes, Gators, Super Bowl Sunday, and the Miracle on Ice: "Pulling together" is associated with lower suicide rates. Journal of Social and Clinical Psychology, 23, 179-195.
Jones, M. I., Dunn, J. G. H., Holt, N. L., Sullivan, P. J., \& Bloom, G. A. (2011). Exploring the '5Cs' of positive youth development in sport. Journal of Sport Behavior, 34, 250-267.

Kamal, A. H., Blais, C., Kelly, P., \& Ekstrand, K. (1995). Self-esteem attributional components of athletes versus nonathletes. International Journal of Sport Psychology, 26, 189-195.

Kelley, S. W., \& Tian, K. (2004). Fanatical consumption: An investigation of the behavior of sports fans through textual data. In L. R. Kahle \& C. Riley (Eds.) Sports marketing and the psychology of marketing communication (pp. 27-65). Mahwah, NJ: Lawrence Erlbaum.

Keyes, C. L. M. (1998). Social well-being. Social Psychology Quarterly, 61, 121-140.

Lambert, N. M., Stillman, T. F., Hicks, J. A., Kamble, S., Baumeister, R. F., \& Fincham, F. D. (2013). To belong is to matter: Sense of belonging enhances meaning in life. Personality and Social Psychology Bulletin, 39, 14181427.

Lavigne, G. L., Vallerand, R. J., \& CrevierBraud, L. (2011). The fundamental need to belong: On the distinction between growth and deficit-reduction orientations. Personality and Social Psychology Bulletin, 37, 1185-1201.

Lee, D., \& Armstrong, K. L. (2008). Gender differences in the factors influencing viewership of televised sports. 
International Journal of Sport Management, 9, 46-66.

Lee, R. M., \& Robbins, S. B. (1998). The relationship between social connectedness and anxiety, selfesteem, and social identity. Journal of Counseling Psychology, 45, 338-345.

Markman, K. D., \& Hirt, E. R. (2002). Social prediction and the "allegiance bias". Social Cognition, 20, 58-86.

Maynard, S. S., \& Kleiber, D. A. (2005). Using leisure services to build social capital in later life: Classical traditions, contemporary realities, and emerging possibilities. Journal of Leisure Research, 37, 475-493.

Melnick, M. J., \& Wann, D. L. (2004). Sport fandom influences, interests, and behaviors among Norwegian university students. International Sports Journal, 8(1), 1-13.

Palmer, C., \& Thompson, K. (2007). The paradoxes of football spectatorship: On-field and online expressions of social capital among the "Grog Squad." Sociology of Sport Journal, 24, 187-205.

Phua, J. (2012). Use of social networking sites by sports fans. Journal of Sports Media, 7, 109-132.

Pringle, A. (2004). Can watching football be a component of developing a state of mental health for men? The Journal for the Royal Society for the Promotion of Health, 124, 122-128.

Reding, F. N., Grieve, F. G., Derryberry, W. P., \& Paquin, A. R. (2011).
Examining the team identification of football fans at the high school level. Journal of Sport Behavior, 34, 378-391. Sherman, D. K., Kinias, Z., Major, B., Kim, H. S., \& Prenovost, M. (2007). The group as a resource: Reducing biased attributions for group success and failure via group affirmation.

Personality and Social Psychology Bulletin, 33, 1100-1112.

Taliaferro, L. A., Rienzo, B. A., Miller, M. D., Pigg, R. M., \& Dodd, V. J. (2010). Potential mediating pathways through which sports participation relates to reduced risk of suicidal ideation. Research Quarterly for Exercise and Sport, 81, 328-339.

Taylor, M. J., \& Turek, G. M. (2010). If only she would play? The impact of sports Participation on self-esteem, school adjustment, and substance use among rural and urban African American girls. Journal of Sport Behavior, 33, 315335.

Theodorakis, N. D., Wann, D. L., Carvalho, M., \& Sarmento, P. (2010).

Translation and initial validation of the Portuguese version of the Sport Spectator Identification Scale. North American Journal of Psychology, 12, 6780.

Theodorakis, N. D., Wann, D. L., Nassis, P., \& Luellen, T. B. (2012). The relationship between sport team identification and the need to belong. International Journal of Sport Management and Marketing. 12, 25-38. 
Wann, D. L. (1997). Sport psychology. Upper Saddle River, NJ: Prentice Hall.

Wann, D. L. (2006a). The causes and consequences of sport team identification. In A. A. Raney \& J. Bryant (Eds.,) Handbook of sports and media (pp. 331-352). Mahwah, NJ: Erlbaum.

Wann, D. L. (2006b). Examining the potential causal relationship between sport team identification and psychological well-being. Journal of Sport Behavior, 29, 79-95.

Wann, D. L. (2006c). Understanding the positive social psychological benefits of sport team identification: The Team Identification - Social Psychological Health Model. Group Dynamics: Theory, Research, and Practice, 10, 272-296.

Wann, D. L., \& Branscombe, N. R. (1993). Sports fans: Measuring degree of identification with the team. International Journal of Sport Psychology, 24, 1-17.

Wann, D. L., Brasher, M., Thomas, D. L., \& Scheuchner, H. L. (in press). Generalizing the Team Identification - Social Psychological Health Model for adolescents. Journal of Sport Behavior.

Wann, D. L., Dimmock, J. A., \& Grove, J. R. (2003). Generalizing the Team Identification - Psychological Health Model to a Different Sport and Culture: The Case of Australian Rules
Football. Group Dynamics: Theory, Research, and Practice, 7, 289-296.

Wann, D. L., Grieve, F. G., End, C., Zapalac, R. K., Lanter, J. R., Pease, D. G., Fellows, B., Oliver, K., \& Wallace, A. (2013). Examining the superstitions of sport fans: Types of superstitions, perceptions of impact, and relationship with team identification. Athletic Insight, 5, 21-44. Wann, D. L., Grieve, F. G., Waddill, P. J., \& Martin, J. (2008). Use of retroactive pessimism as a method of coping with identity threat: The impact of group identification. Group Processes \& Intergroup Relations, 11, 439-450.

Wann, D. L., Grieve, F. G., Zapalac, R. K., \& Pease, D. G. (2008). Motivational profiles of sport fans of different sports. Sport Marketing Quarterly, 17, 619.

Wann, D. L., Keenan, B., \& Page, L. (2009). Testing the Team Identification Social Psychological Health Model: Examining non-marquee sports, seasonal differences, and multiple teams. Journal of Sport Behavior, 32, 112-124.

Wann, D. L., Melnick, M. J., Russell, G. W., \& Pease, D. G. (2001). Sport fans: The psychology and social impact of spectators. New York: Routledge.

Wann, D. L., \& Pierce, S. (2005). The relationship between sport team identification and social well-being: Additional evidence supporting the Team Identification - Social 
Psychological Health Model. North American Journal of Psychology, 7, 117124.

Wann, D. L., Rogers, K., Dooley, K., \& Foley, M. (2011). Applying the Team Identification - Social Psychological Health Model to older sport fans. The International Journal of Aging and Human Development, 72, 303-315.

Wann, D. L., Waddill, P. J., Polk, J., \& Weaver, S. (2011). The Team Identification - Social Psychological Health Model: Sport fans gaining connections to others via sport team identification. Group Dynamics: Theory, Research, and Practice, 15, 75-89.

Wann, D. L., \& Weaver, S. (2009).

Understanding the relationship between sport team identification and dimensions of social well-being. North American Journal of Psychology, 11, 219-230.

Wann, D. L., Weaver, S., Belva, B., Ladd, S., \& Armstrong, S. (2015). Investigating the impact of team identification on the willingness to commit verbal and physical aggression by youth baseball spectators. Journal of Amateur Sport, 1(1), 1-28.

Wigfield, A., \& Eccles, J. S. (1994).

Children's competence beliefs, achievement values, and general selfesteem change across elementary and middle school. The Journal of Early Adolescence, 14, 107-138.

Wigley, B. J., Sagas, M., \& Ashley, F. B. (2002). A study of collegiate baseball:

Examining sport fan motivation and marketing implications. International Journal of Sport Management, 3, 90-102. 


\section{Tables}

Table 1

Potential Ranges, Means, Standard Deviations, and Cronbach's Reliability Alphas for the Dependent Measures.

$\begin{array}{lcccc} & \text { Potential } & & \\ \text { Measure } & \text { Range } & \text { Mean } & \text { SD } & \text { Alpha } \\ \text { Percentage of Friends } & 0 \text { to } 200 & 113.88 & 62.23 & .875 \\ \text { Number of Friends } & 0 \text { to N/A } & 43.58 & 43.58 & .876 \\ \text { Likert-scale Index } & 6 \text { to } 48 & 27.85 & 12.83 & .960 \\ \text { SSIS } & 7 \text { to } 56 & 35.55 & 14.40 & .939 \\ \text { SSLS } & 5 \text { to } 35 & 27.33 & 6.20 & .899 \\ \text { - } & & & \end{array}$


Table 2

Intercorrelations among Percentage of Friends, Number of Friends, Likert-scale Index, Team Identification, Social Life Satisfaction, and Membership on the Football Team

$\begin{array}{llllll}1 & 2 & 3 & 4 & 5 & 6\end{array}$

Percentage of Friends (1)

Number of Friends (2) $\quad .46^{* * *} \quad--$

Likert-scale Index (3) $\quad .65^{* * *} \quad .51 * * * \quad--$

$\begin{array}{lllll}\text { Team Identification (4) } & .68^{* * *} & .50^{* * *} & .81 * * * & --\end{array}$

Social Life Satisfaction (5) $\quad .22^{* *} \quad .10 \quad .16^{*} \quad .19 * * \quad--$

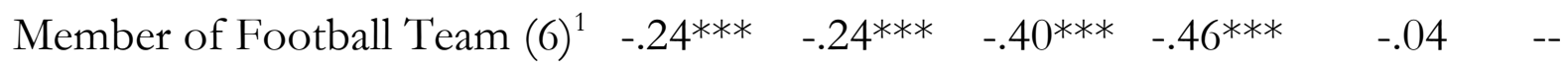

Notes: ${ }^{1}$ Member of football team coded as $1=$ yes, $2=$ no. $*=p<.05 ; * * p<.01 ; * * *$ $=p<.001$. 